\title{
Queue Design of Bank Teller Service in Banten, Indonesia
}

\author{
Supriyadi Supriyadi ${ }^{1}$, Salman Alfarisi ${ }^{2}$, Rano Karno ${ }^{3}$, Dadi Cahyadi ${ }^{4}$ \\ \{supriyadimti@gmail.com¹, salman.alfarisi@umk.ac.id ${ }^{2}$, ranokarno54@gmail.com\} \\ Universitas Serang Raya, Jalan Raya Serang, Cilegon KM. 5, Kota Serang, Banten $42116^{13}$, \\ Universitas Muria Kudus, Jl. Lkr. Utara UMK, Gondang Manis, Bae, Kudus, Jawa Tengah $59327^{2}$
}

\begin{abstract}
This study aims to create a queuing system engineering during peak hours. The analysis was done by using queuing theory method with $\mathrm{M} / \mathrm{M} / \mathrm{S}$ calculation. The calculation is to get the average service time, average waiting time, and queue structure. The result of this research is the average service time per person 5 minutes and average waiting per person 13 minutes The standard service time for each customer is two minutes.. The system engineering is done by making 2 queue lines, where the first line for the client queue that carries less than 2 transaction applications with 1 Teller and the second line for queue is more than equal to 3 application transactions with 3 Teller. Queue analysis based on consumer behavior is able to optimize bank services without having to add service servers.
\end{abstract}

Keywords: queue, transaction, service, system engineering, teller.

\section{Introduction}

The survey shows waiting times, convenience and bank staff services are factors that influence customers in choosing a bank [1]. Fast transactions greatly affect the convenience of customers. A Teller bank is expected to serve customers quickly so it does not cause the queue too long. Very long queue make the customer feel uncomfortable, considering their time wasted when they queue up before being served.

Research on queuing system of bank teller service has been done, such as queue at Indian bank [2], South Africa [3] Ethiopia [4], Ghana [5], and Indonesia [6]. The research results is the addition of server service so that the length of queue is reduced. This is reinforced by the research conducted by Haoaa \& Yifeib [7] that by using business process reengineering, optimal services are obtained based on simulations and the entire situation uses six servers at Nanjing Branch Commercial Bank. Based on the simulation process, an increase in service utilities in Malaysian banks can be done by increasing the number of services and removing the service table and standardizing the shift of all counters [2]. There is a little research about the queues that provide solutions to organize the system so that the queue is reduced without adding service server. This research tries to set existing queue system based on service user characteristic without increasing number of service server.

The queue system at one Banks in Banten based on arrival, where the first come first served and using multi channel, while for the process there is one stage (single phase). Queue lines in Teller are distinguished by queue type, ie public lane and cash deposit. There are five

ICCSET 2018, October 25-26, Kudus, Indonesia

Copyright (C) 2018 EAI

DOI 10.4108/eai.24-10-2018.2280631 
Teller to conduct transactions. The one is Teller for cash deposit and four Teller for general transaction. The standard service time for each customer is two minutes.

\section{Theoretical Background}

The queuing process is a process related with the arrival of a customer at a service facility, then waits in a row (queue) if all services are busy, and finally leaves the facility [8][10]. Queues exist because the needs for services beyond the capacity or service facilities are busy. Bank queues are influenced by the number of queues, number of services, and optimal level of service [11].

Discipline queuing is the rule by which customers are served, or service discipline that includes the order of the customers receiving the service [12]-[14]. The queuing discipline discusses the policies under which customer are selected from the queue to be served, based on the order of arrival of the customer. There are four forms of service discipline commonly used in practice, namely:

a. First Come First Served (FCFS) or First In First out (FIFO) ie the customer who comes first will be served, such as queuing system at Bank, gas station, cinema ticket purchase, etc.

b. Last Come First Served (LCFS) or Last In First Out (LIFO) is the last customer queuing system will be served first. For example the queue system in the elevator for the same floor

c. Service In Random Order (SIRO) is a call based on chance at random, no matter who comes first, usually arises in a practical state

d. Priority Service (PS) is the service given to those who have higher priority than those with lower priority, even though it has already arrived in the waiting line.

Based on the nature of the service process, it can be classified service facilities in the arrangement of channel (single or multiple) and phase (single or multiple) which will form a different queue structure. There are four basic queue structure models that are common in all queuing systems[15]-[17] ie:

1. Single Channel-Single Phase. Single channel means that there is only one path to enter the service system or there is one service facility.

2. Single Channel-Multiphase. Multiphase shows there are two or more services performed sequentially (in phase-phase), such as in car wash, car painters, mass production lines and so on.

3. Multichannel-Single Phase. A multichannel-single phase system occurs whenever two or more service facilities are fed by a single queue. For example ticket counter that can be served by some officers, etc.

4. Multichannel-Multiphase. This multichannel-multiphase system has several service facilities at each stage, so that more than one individual can be served at a time. 


\section{Research Method}

This research was conducted in a Government Bank, Cilegon, Banten. Data collection was carried out for 5 days, start on Monday to Friday from 05 to 09 June 2017. This research method uses double track queue system (M / M / S). Before the data processing, data adequacy test and distribution fit test were done. The data adequacy test is used to determine whether the amount of data is sufficient or not sufficient [18], [19]. Chi Square test to know the distribution in accordance with the group of frequencies observed with the group of frequency assumed as expected then performed matching test distribution [19].

$$
N^{\prime}=\left[\frac{\frac{k}{s} \sqrt{N\left(\sum x^{2}\right)-\left(\sum x\right)^{2}}}{\sum x}\right]^{2}
$$

$\mathrm{N}^{\prime} \quad$ : The amount of theoretical data (minimum data observation)

$\mathrm{N}$ : Number of observed data

$\mathrm{K}$ : Confidence level $(95 \%, \mathrm{k}=2)$

$\mathrm{S}$ : Degree of observational accuracy $(5 \%)$

$\mathrm{X}$ : Observation data

$\mathrm{N}>\mathrm{N}^{\prime}$

$$
X^{2}=\sum_{i=1}^{b} \sum_{j=1}^{k} \frac{(O i j-E i j)^{2}}{E i j}
$$

Oij : the number of clients observed in row i column $\mathrm{j}$

Eij : number of expected customers in row $\mathrm{i}$ column $\mathrm{j}$

$\mathrm{b}$ : number of rows

$\mathrm{k}$ : number of columns

$\mathrm{X}^{2}$ : chi square

The value of Eij can be searched:

$$
\mathrm{E}_{\mathrm{ij}}=\frac{(n i 0 \times n 0 j)}{n}
$$

The test criterion is $\mathrm{H}_{0}$ accepted, if $\mathrm{x}^{2}$ count $\left\langle\mathrm{x}^{2}\right.$ table. $\mathrm{H}_{0}$ is rejected, if $\mathrm{x}^{2}$ count $>\mathrm{x}^{2}$ table with the real level $\alpha=5 \%$, and the degree of freedom (d.f) $=(b-1)(k-1)$. Assuming that customers waiting for service form a single line and will be served on the service station that was first available at that time [20], [21]. Multiple line queue models are found in most banks. A public pathway is created, and the first-line customer is first served by the teller.

$$
\begin{gathered}
\mathrm{P} 0=\frac{1}{\left[\sum_{n=0}^{M-1} \frac{1}{n !}\left(\frac{\lambda}{\mu}\right) n\right]+\frac{1}{M !}\left(\frac{\lambda}{\mu}\right) M \frac{M \mu}{M \mu-\lambda}} \text { to } M \mu>\lambda \\
\mathrm{Ls}=\frac{\lambda \mu\left(\frac{\lambda}{\mu}\right)^{M}}{(M-1) !(M \mu-\lambda)^{2}} \mathrm{P} 0+\frac{\lambda}{\mu} \\
\mathrm{Ws}=\frac{\lambda \mu\left(\frac{\lambda}{\mu}\right)^{M}}{(M-1) !(M \mu-\lambda)^{2}} \mathrm{P} 0+\frac{\lambda}{\mu}=\frac{L s}{\lambda}
\end{gathered}
$$




$$
\begin{array}{r}
\mathrm{Lq}=\mathrm{Ls}-\frac{\lambda}{\mu} \\
\mathrm{Wq}=\mathrm{Ws}-\frac{1}{\mu}-\frac{L q}{\lambda}
\end{array}
$$

$\lambda \quad$ : Total arrival time average unity

$\mu \quad$ : Number of people served time union

Ls : The number of average customers in the system (who are waiting to be served)

Ws : The average amount of time spent in the system (waiting time plus service time)

Lq : The number of average units waiting in the queue

$\mathrm{Wq}$ : Average time spent waiting in queue

$\mathrm{P}$ : System utilization factor

Po : Probability is 0 units in system (empty service unit)

\section{$4 \quad$ Result and Discussion}

The observation data from the Bank is tested to determine the accuracy. In the calculation of the test data adequacy is also required level of accuracy and level of confidence. In the work measurement activity will be taken 5\% accuracy and 95\% confidence level.

Based on the calculation results obtained the minimum number of observations $\left(\mathrm{N}^{\prime}\right)$ is 169 , while the number of observed data $(\mathrm{N})$ is 183 . Because the number of observed data more than minimum required data $\left(\mathrm{N}>\mathrm{N}^{\prime}\right)$, it can be concluded that the data taken is enough. Sufficient data will be processed to the next stage which is calculation of chi square test. The calculation is to know the distribution of poisson and exponential in arrival or service.

From Table 1 the number of arrivals (n) and frequency of observation (fn) generated will be obtained the probability of arrival (pn) and the expected frequency (en) to determine the value of chi square $\left(\mathrm{x}^{2}\right)$. Based on calculations obtained the results of many chi square test arrival that can be seen in Table 1 , that the value of $x^{2}$ count $=16,1674<19,675=x^{2}$ table, then $\mathrm{H}_{0}$ accepted and $\mathrm{H}_{1}$ rejected. Thus the probability distribution for many clients arrives distributed Poisson.

The probability distribution of service time is determined by using service time data. The probability distribution of service time is tested by Chi Square test which is shown in Table 2. Table 2 use chi square test of service time. It can be seen that the value of $\mathrm{x}^{2}$ count $=26.8138>$ $16.919=\mathrm{x}^{2}$ table, then $\mathrm{H}_{1}=$ received and $\mathrm{H}_{0}$ is rejected. Thus the probability distribution for service time is not exponentially distributed.

Table 1. Chi square test for many arrival distribution test

\begin{tabular}{ccccc}
\hline $\mathrm{N}$ & $\mathrm{f}_{\mathrm{n}}$ & $\mathrm{p}_{\mathrm{n}}$ & $\mathrm{e}_{\mathrm{n}}$ & $\mathrm{X}^{2}$ \\
\hline 0 & 0 & 0,0263 & 0,2893 & 0,2893 \\
1 & 4 & 0,0958 & 1,0538 & 8,2369 \\
2 & 2 & 0,1742 & 1,9162 & 0,0036 \\
3 & 0 & 0,2111 & 2,3221 & 2,3221 \\
4 & 0 & 0,1919 & 2,1109 & 2,1109 \\
5 & 3 & 0,1396 & 1,5356 & 1,3965
\end{tabular}




\begin{tabular}{ccccc}
6 & 1 & 0,0846 & 0,9306 & 0,0051 \\
7 & 0 & 0,0439 & 0,4829 & 0,4829 \\
8 & 0 & 0,0199 & 0,2189 & 0,2189 \\
9 & 0 & 0,0081 & 0,0891 & 0,0891 \\
10 & 0 & 0,0029 & 0,0319 & 0,0319 \\
11 & 1 & 0,0009 & 0,0099 & 0,9802 \\
\hline
\end{tabular}

Table 2. Chi square test for service time distribution test.

\begin{tabular}{|c|c|c|c|c|c|c|c|}
\hline $\begin{array}{c}\text { Service } \\
\text { Time } \\
(x)\end{array}$ & $\begin{array}{c}\text { Middle } \\
\text { value } \\
\left(x_{i}\right)\end{array}$ & $\begin{array}{l}\text { Freq. } \\
\text { Obs } \\
\left(f_{i}\right)\end{array}$ & $\begin{array}{c}\text { Freq. } \\
\text { Relatively } \\
\left(f_{r}\right)\end{array}$ & $x_{i} . f_{i}$ & $\begin{array}{c}\text { Freq. } \\
\text { Theoretical } \\
\left(f_{e}\right)\end{array}$ & $\left(f_{i}-f_{e}\right)^{2}$ & $x^{2}$ \\
\hline $0-99$ & 49,5 & 0 & 0 & 0 & 10,571 & 111,746 & 10,571 \\
\hline $100-199$ & 149,5 & 11 & 1,275 & 1644,5 & 7,752 & 10,5495 & 1,3608 \\
\hline $200-299$ & 249,5 & 12 & 0,3 & 2994 & 5,684 & 39,8918 & 7,0182 \\
\hline $300-399$ & 349,5 & 6 & 0,15 & 2097 & 4,172 & 3,3416 & 0,8009 \\
\hline $400-499$ & 449,5 & 7 & 0,175 & 3146,5 & 3,06 & 15,5236 & 5,0730 \\
\hline $500-599$ & 549,5 & 2 & 0,05 & 1099 & 2,244 & 0,0595 & 0,0265 \\
\hline $600-699$ & 649,5 & 0 & 0 & 0 & 1,648 & 2,7159 & 1,648 \\
\hline $700-799$ & 749,5 & 1 & 0,025 & 749,5 & 1,208 & 0,0433 & 0,0358 \\
\hline $800-899$ & 849,5 & 0 & 0 & 0 & 0,884 & 0,7814 & 0,0884 \\
\hline $900-999$ & 949,5 & 1 & 0,025 & 949,5 & 0,648 & 0,1239 & 0,1912 \\
\hline Amount & 4995 & 40 & 1 & 12680 & & & 26,8138 \\
\hline
\end{tabular}

A Bank in Banten uses a Multichannel-Single phase queue structure with 4 persons as Teller, so for calculations it can be completed using M / M / S where in multiple pathway models are often found two or more service stations available to handle customers. Assuming that customers waiting for service form a single line and will be served on the service station that was first available at that time.

The number of service facilities is four and there is only one path where each customer carrying one or more transactions in one line so that the result of average arrival $(\lambda)=44$, average service $(\mu)=12$ and the number of services $s=4$, then obtained with the result that is the usefulness level of service facility $(P)=92 \%$, the probability no customers in the system $(\mathrm{P} 0)=0.91 \%$, the average number of subscribers in the queue $(\mathrm{Lq})=9$, the average number of subscribers in the system $(\mathrm{Ls})=13$, the average time customers spend in the queue $(\mathrm{Wq})=$ 12.6, the average time spent by customers in the system $(\mathrm{Ws})=17.4$ and the probability of waiting in the queue $(\mathrm{Pw})=82.65 \%$.

The teller's queue system use multi channel-Single Phase, where there are four service facilities and there is only one path for every customer who will transact. Customers who transact can bring one or more application transactions and enter a queue line that has been 
provided to wait before getting service. The result of the system is already known the value and the amount above, that with four Teller using one line has the average value of the number of subscribers in the queue $(\mathrm{Lq})=9$, the average time spent by customers in the queue $(\mathrm{Wq})=$ 12.6 and etc. The problem will be solved with dividing the queue path based on the number of transaction applications that the customer does.

Teller queue line with four Teller originally there is one queue line for general transactions will be divided into two lanes to transact. Client transactions that are less than equal to two transaction applications will enter queue line with one Teller service and customer transaction more than equal to three transaction application will enter queue line with service of three Teller.

Based on Table 3. it can be seen that the number of servers four and there is only one queue line the value is higher than the two queue lines, where one queue path consists of the number of three servers with transactions greater than equal to three and one queue line again consisting of one server with transactions less than equal to two. The conclusion that it will be more optimal Teller service to the customer if the Bank uses four Teller with divided into two lines queue based on the number of transactions. Consumer behavior that carries more than one application affects the length of the queue and service. Queue engineering based on consumer behavior is able to optimize bank services without having to add service servers as was done in previous studies.

Table 3. Comparison of queue system performance.

\begin{tabular}{cccc}
\hline \multirow{2}{*}{ Performance } & \multicolumn{3}{c}{ Server } \\
& 4 & $3 \geq 3$ Transaction & $1 \leq 2$ Transaction \\
\hline P & 0,92 & 0,87 & 0,9 \\
Lq & 9,04 & 4,93 & 8,1 \\
Ls & 12,71 & 7,53 & 9 \\
Wq & 0,21 & 0,19 & 0,2 \\
Ws & 0,29 & 0,29 & 0,25 \\
\hline
\end{tabular}

\section{Conclusion}

The result of this aproach is to make 2 queue process line, where the first line for queue process of client which carry less than equal to 2 transaction application with 1 Teller service and second line for queue process more than equal to 3 transaction application with 3 Teller service. Average customer waiting time is 13 minutes per person and Teller service to the customer has an average time of 5 minutes per person, after the simulation as above, for 3 Teller, the average customer waiting time is 11 minutes per person, the average service time of Teller to 6 minutes per person and for 1 Teller obtained average customer waiting time to 12 minutes per person while the average Teller service to 3 minutes per person. Queue analysis based on consumer behavior is able to optimize bank services without having to add service servers. This research can be continued by analyzing teller to get effective work processes in serving bank customers.

\section{References}


[1].H. Xiao and G. Zhang, "The queuing theory application in bank service optimization," in Logistics Systems and Intelligent Management, 2010 International Conference on, 2010, vol. 2, pp. 1097-1100.

[2] N. Madadi, A. H. Roudsari, K. Y. Wong, and M. R. Galankashi, "Modeling and simulation of a bank queuing system," in Computational Intelligence, Modelling and Simulation (CIMSim), 2013 Fifth International Conference on, 2013, pp. 209-215.

[3] H. R. Bakari, H. A. Chamalwa, and A. M. Baba, "Queuing process and its application to customer service delivery (A case study of Fidelity Bank Plc, Maiduguri)," Int. J. Math. Stat. Invent., vol. 2, no. 1, pp. 14-21, 2014.

[4] E. Berhan, "Bank Service Performance Improvements using Multi-Server Queue System," IOSR J. Bus. Manag., vol. 17, no. 6, pp. 65-69, 2015.

[5] W. Agyei, C. Asare-Darko, and F. Odilon, "Modeling and Analysis of Queuing Systems in Banks:(A case study of Ghana Commercial Bank Ltd. Kumasi Main Branch)," Econ. Anal., vol. 1, p. $2,2015$.

[6] C. I. Setiawati and F. A. Budyanna, "Counting Teller Quantity for Better Queue in Financial Institution: Case of Bank Central Asia, Metro Indah Mall Branch Office-Bandung," J. Bisnis dan Manaj., vol. 18, no. 2, pp. 65-72, 2017.

[7] T. Hao and T. Yifei, "Study on queuing system optimization of bank based on BPR," Procedia Environ. Sci., vol. 10, pp. 640-646, 2011.

[8] R. Bronson and G. Naadimuthu, "Operations research, Schaum's outlines." McGraw Hill, New York, 1997.

[9] A. Senderovich, M. Weidlich, A. Gal, and A. Mandelbaum, "Queue mining-predicting delays in service processes," in International Conference on Advanced Information Systems Engineering, 2014, pp. $42-57$.

[10] T. A. Koka and V. H. Badshah, "Analysis of queuing theory in a bank," IJAR, vol. 2, no. 8, pp. 731-734, 2016.

[11] X. G. Wang and Z. C. Jiao, "Research based on queuing theory of the problem of bank," Xiangtan Norm. Univ., vol. 30, no. 1, pp. 58-60, 2008.

[12] A. K. Sharma and G. K. Sharma, "Queueing theory approach with queueing model: a study," Int. J. Eng. Sci. Invent., vol. 2, no. 2, pp. 1-11, 2013.

[13] O. Boxma, J. Bruin, and B. Fralix, "Sojourn times in polling systems with various service disciplines," Perform. Eval., vol. 66, no. 11, pp. 621-639, 2009.

[14] Y. Lu, Q. Xie, G. Kliot, A. Geller, J. R. Larus, and A. Greenberg, "Join-Idle-Queue: A novel load balancing algorithm for dynamically scalable web services," Perform. Eval., vol. 68, no. 11, pp. 1056-1071, 2011.

[15] A. Borodin, J. Kleinberg, P. Raghavan, M. Sudan, and D. P. Williamson, “Adversarial queuing theory," J. ACM, vol. 48, no. 1, pp. 13-38, 2001.

[16] V. V Kalashnikov, Mathematical methods in queuing theory, vol. 271. Springer Science \& Business Media, 2013.

[17] A. Y. Khinchin, D. M. Andrews, and M. H. Quenouille, Mathematical methods in the theory of queuing. Courier Corporation, 2013.

[18] Z. Lai, S.-C. Cheung, and W. K. Chan, "Inter-context control-flow and data-flow test adequacy criteria for nesc applications," in Proceedings of the 16th ACM SIGSOFT International Symposium on Foundations of software engineering, 2008, pp. 94-104.

[19] B. Jiang and W. K. Chan, "On the integration of test adequacy, test case prioritization, and statistical fault localization," in Quality Software (QSIC), 2010 10th International Conference on, 2010, pp. 377-384.

[20] Y. W. Shin and T. S. Choo, "M/M/s queue with impatient customers and retrials," Appl. Math. Model., vol. 33, no. 6, pp. 2596-2606, 2009.

[21] M. Armony, E. Plambeck, and S. Seshadri, "Sensitivity of optimal capacity to customer impatience in an unobservable M/M/S queue (Why you shouldn't shout at the DMV)," Manuf. Serv. Oper. Manag., vol. 11, no. 1, pp. 19-32, 2009. 